\title{
The overexpression of maspin increases the sensitivity of lung adenocarcinoma drug-resistant cells to docetaxel in vitro and in vivo
}

\author{
Qian Sun ${ }^{1}$, Kai Zhang ${ }^{2}$, Huan Li ${ }^{1}$, Weiwei Chen ${ }^{1}$, Leilei Liu ${ }^{3}$, Guichun Huang ${ }^{2}$, Qun Zhang ${ }^{2}$, Jing Wang ${ }^{1}$, \\ Lu Lu ${ }^{1}$, Longbang Chen ${ }^{1}$, Rui Wang ${ }^{1}$ \\ ${ }^{1}$ Department of Medical Oncology, Jinling Hospital, Nanjing Medical University, Nanjing, China; ${ }^{2}$ Department of Medical Oncology, Jinling Hospital, \\ Medical School of Nanjing University, Nanjing, China; ${ }^{3}$ Department of Pathology, Jinling Hospital, Nanjing Medical University, Nanjing, China \\ Contributions: (I) Conception and design: Q Sun, R Wang; (II) Administrative support: K Zhang, H Li; (III) Provision of study materials or patients: \\ Q Sun, W Chen, G Huang; (IV) Collection and assembly of data: Q Sun, Q Zhang, J Wang; (V) Data analysis and interpretation: Q Sun, L Lu, L \\ Chen; (VI) Manuscript writing: All authors; (VII) Final approval of manuscript: All authors. \\ Correspondence to: Longbang Chen; Rui Wang. Department of Medical Oncology, Jinling Hospital, Nanjing Medical University, Nanjing, China. \\ Email: dr.chenlb@163.com; wangrui218@163.com.
}

Background: In this study, we found that maspin affects the development of drug resistance in lung adenocarcinoma. Therefore, it is important to clarify the role and mechanism of mammary serine protease inhibitor (maspin) in the regulation of adenocarcinoma drug resistance in order to improve individualized clinical treatment protocols and drug resistance interventions.

Methods: Immunohistochemical was used to detect maspin expression in tissue chip samples of 75 patients diagnosed with lung adenocarcinoma and treated with a taxus chemotherapy regimen, and the correlation between maspin, clinicopathological factors, and prognosis was analyzed. The expression of maspin in a human lung adenocarcinoma docetaxel-resistant cell line, SPC-A1/DTX, and its parent cells were detected by reverse transcription polymerase chain reaction (RT-PCR) and western blot assay. MTT and flow cytometry were used to detect the effects of knockdown or overexpression of maspin on chemotherapy sensitivity and apoptosis in lung cancer cells. Tumor cells were also analyzed in vivo to determine their tumorigenic ability and susceptibility to docetaxel.

Results: Maspin is poorly expressed in lung adenocarcinoma tissue chips that have received a taxus chemotherapy regimen, and is also closely related to poor grading, late stage, lymph node metastasis, and poor prognosis. Maspin has a low expression in drug-resistant cells, and the expression level of maspin decreases significantly with increases in docetaxel concentration and over time. In drug-resistant cells, knockdown of maspin can significantly affect the sensitivity of drug-resistant cells to docetaxel. In the chemotherapy-sensitive strain SPC-A1, maspin was mainly located in the cell nucleus, while in the chemotherapy-resistant strain SPC-A1/DTX, maspin was mainly located in the cytoplasm. An in vivo nude mouse xenograft model showed that an overexpression of maspin significantly increased the inhibitory effect of docetaxel on tumor-bearing tissues and the apoptosis rate, and markedly reduced tumor weight, volume, and the Ki-67-positive rate.

Conclusions: In vitro and in vivo experiments show that overexpression of maspin can increase the sensitivity of lung cancer drug-resistant cells to chemotherapy drugs, suggesting that the expression level of maspin could be used as a molecular marker to predict lung cancer drug resistance to docetaxel.

Keywords: Lung cancer; maspin; drug resistance; proliferation; docetaxel

Submitted Sep 27, 2020. Accepted for publication Nov 17, 2020.

doi: $10.21037 /$ atm-20-7053

View this article at: http://dx.doi.org/10.21037/atm-20-7053 


\section{Introduction}

Lung cancer is a condition characterized by malignant tumor growth and is the leading cause of morbidity and mortality in the past decade (1). Even with advances in new technologies, methods, and medications, chemotherapy still plays an important role in the treatment of lung adenocarcinoma (2). With the application of paclitaxel, docetaxel, gemcitabine, and other third-generation clinical chemotherapy drugs, the remission rate of non-small cell lung cancer (NSCLC) patients has improved. Specifically, the objective response rate (ORR) of docetaxel combined with platinum for advanced NSCLC is $40 \%$, and the progression-free survival (PFS) period is approximately 4 months (3). However, in clinical practice, over $50 \%$ of lung cancer patients have a poor initial response to chemotherapy with moderate efficacy, and poor efficacy (multi-drug resistance) when receiving subsequent chemotherapy. Moreover, a small proportion of patients exhibit resistance to any chemotherapy drug (primary resistance), which can cause sustained disease progression $(4,5)$. The resistance of tumor cells to chemotherapy drugs, also known as chemotherapy resistance, is the main reason for poor efficacy or failure of treatment and is the most important impediment restricting the efficacy of chemotherapy. To date, the mechanism of chemotherapy resistance remains unclear (6-8), and the ongoing challenge in cancer research has been to explore and clarify the mechanism of multidrug resistance. It is also important to clarify the regulatory role of the relevant signal axis and the key targets of drug resistance, and to either find ways to improve chemotherapy sensitivity or to reverse drug resistance.

The mammary serine protease inhibitor (maspin) gene is a gene encoding serine protease inhibitor which was isolated from human normal mammary muscle epithelial cells by Zou et al. in 1994 (9). As a newly discovered tumorsuppressor gene, it has attracted increasing attention in recent years. The tumor-inhibition function of maspin mainly manifests in three main aspects. (I) It can promote apoptosis by selectively controlling the stability of Bcl-2 and BAX, breaking the delicate balance between these apoptotic proteins, thereby inhibiting cancer (10). (II) It can reduce cell movement by participating in the formation of adhesive plaques which inhibits the metastasis of tumor cells (11), and can further affect the degradation of the extracellular matrix and basement membranes (12). (III) It can increase cell adhesion through intracellular and extracellular signal regulation pathways (13).
In recent years, studies have shown that maspin participates in the regulation of tumor resistance to chemotherapy drugs. Gan et al. found that maspin regulated paclitaxel resistance in prostate cancer through the PTEN/ maspin pathway. The overexpression of PTEN caused cell apoptosis, and the pro-apoptotic effect of PTEN on paclitaxel-induced cell apoptosis could be eliminated by maspin knockdown (14). However, whether maspin is involved in multidrug resistance in lung adenocarcinoma chemotherapy is still unknown.

This aim of this study was thus to explore the correlation between maspin and the clinical prognosis of patients with lung adenocarcinoma. Interference and overexpression techniques were used to analyze the relationship between maspin expression levels and the susceptibility of lung adenocarcinoma cells to different chemotherapeutic drugs by way of an in vitro cell model and an in vivo animal model. A further aim was to explore the molecular mechanism of maspin and its possible role in the formation of multidrugresistance phenotypes in human lung adenocarcinoma cells in the hope that this may lead to new approaches in the individualized chemotherapy treatment of lung adenocarcinoma patients. We present the following article/ case in accordance with the ARRIVE reporting checklist (available at http://dx.doi.org/10.21037/atm-20-7053).

\section{Methods}

\section{Collection of clinical samples}

The tissue chips of 75 primary lung adenocarcinoma patients (product no. Hlug-Ade150Sur-01) were acquired from the Shanghai Xinchao Biotechnology Co., Ltd., each of which was $1.5 \mathrm{~mm}$ in diameter and $4 \mu \mathrm{m}$ in thickness. Patients were 39 males and 36 females, aged 20-84 years (median age $=59$ years). The grading standards refer to the tumor grading standards recommended by the World Health Organization in 2000, and the staging is in accordance with the eighth edition of the TNM staging method revised by the International Association for the Study of Lung Cancer (IASLC) in 2016. All included patients had received treatment with taxus chemotherapy drugs. The included patients satisfied the following conditions: they had received neoadjuvant chemotherapy before surgery or adjuvant chemotherapy within 6 months after surgery, comprising paclitaxel (including paclitaxel liposomes) $\left(135-200 \mathrm{mg} / \mathrm{m}^{2}\right)$ or docetaxel $\left(70-75 \mathrm{mg} / \mathrm{m}^{2}\right)$ combined with platinum, and cisplatin $\left(100 \mathrm{mg} / \mathrm{m}^{2}\right)$ and 
carboplatin (AUC5) for more than 6 cycles (every 3 weeks). The follow-up time was 5 to 8 years, with surgery being undertaken between July 2004 and September 2007. Follow-up concluded on July 31, 2012.

\section{Cell lines}

The human lung adenocarcinoma cell line SPC-A1 was purchased from the Shanghai Institute of Cell Biology, Chinese Academy of Sciences. The human lung adenocarcinoma docetaxel-resistant cell line, SPC-A1/ DTX, was self-built and preserved in our laboratory in the early stage through the following steps of gradual induction: Over a 14-month period, docetaxel was gradually increased to maintain concentration from an initial concentration of $0.008 \mu \mathrm{g} / \mathrm{L}$ to a final stabilized and tolerated concentration of $5 \mu \mathrm{g} / \mathrm{L}$ in the human lung adenocarcinoma SPC-A1 cells. Drug-resistant cells were named SPC-A1/Docetaxel (SPC-A1/DTX), corresponding to their parent cells, SPC-A1 (sensitive cell lines). The drug concentration continued to be increased in vitro to maintain the drugresistant cell phenotype, and the current maintenance docetaxel drug concentration of the cell line reached $50 \mu \mathrm{g} / \mathrm{L}$. Cell lines were cultured in a RPMI 1640 medium supplemented with $10 \%$ fetal bovine serum, $100 \mathrm{U} / \mathrm{mL}$ penicillin, and $100 \mu \mathrm{g} / \mathrm{mL}$ streptomycin at $37{ }^{\circ} \mathrm{C}$ with $5 \% \mathrm{CO}_{2}$. The cell culture medium was changed every 1 to 2 days. Drugs with maintained drug concentration were added to drug-resistant cells, and the cells at logarithmic growth stage were subcultured according to the cell growth status at a 1:2 to $1: 5$ ratio.

The study was conducted in accordance with the Declaration of Helsinki (as revised in 2013).

\section{Vector construction and transfection}

pGEX6P1-HA-MEK1-maspin plasmid (hereinafter referred to as pGEX6P1/maspin) and corresponding blank vector plasmid control (pGEX6P1/control) were purchased from, and constructed by, the Addgene Company (USA). The intracellular activated region fragment of maspin was inserted into the vector so that transfected cells could express maspin continuously and efficiently. Neomycin resistance assisted in stabilizing the transfected cell line screening.

The short hairpin RNA (shRNA) expression vector (Shanghai Jima Pharmaceutical Technology Co., Ltd.) was used to construct the pGPU6/eGFP/Neo-shMaspin (hereinafter referred to as pGPU6-shMaspin) and the corresponding blank vector plasmid control (pGPU6shcontrol). Neomycin was used to help screen and stabilize the transfected cells. The interference sequences of pGPU6-shMaspin in this study were as follows: GCACAAGGATGAATTGAAT, forward primer 5'-ATCA AGCTTCGGATGCCCCTGCAACTAGCAAATTC-3', reverse primer 3'-GGGATTGAATTCTTAAGGAGAACA GAATTTGCC-5'.

\section{The detection of maspin mRNA expression by RT-PCR assay}

Paracancer tissues, cancer tissues, and cell lines were collected, and the total RNA was extracted with the total RNA extraction kit. The operation was carried out in strict accordance with the instructions. Complementary DNA (cDNA) was obtained by reverse transcription polymerase chain reaction (RT-PCR) using a reverse transcription kit. The SYBR green dye method was used for the RT-PCR reaction. The relative expression levels of maspin were calculated by $\triangle \triangle \mathrm{Ct}$, and $\beta$-actin was used as the internal reference. The internal reference GAPDH primers refer to the reference (15). The primer design software Primer 5.0 and Primer bank were used to query and design primers according to the cDNA sequence of human genes in Genebank. The primers were synthesized by the Shanghai Sangon biotechnology Co., Ltd: forward primer: 5'-GGT CAGATCAACAACTCAATTAAGG-3'; reverse primer: 5'-CCAACAAAGTAGGCAGCATTAAC-3'.

\section{Western blot detection}

The cells were collected, and lysis buffer was added. After the cells were fully lysed, the lysate was collected and centrifuged in a centrifuge tube at $4{ }^{\circ} \mathrm{C}$ for $15 \mathrm{~min}$ at $12,000 \mathrm{rpm}$. The total protein of the cells was collected, and then the protein concentration was detected by the bicinchoninic acid (BCA) method. A $60 \mu \mathrm{g}$ loading quantity of the sample was added to each well and a $10 \%$ polyacrylamide gel was used for the protein electrophoresis. The electrophoresis voltage was set at a $90 \mathrm{~V}$ and $120 \mathrm{~V}$ constant voltage. After completion, the membrane was transferred to the polyvinylidene fluoride (PVDF) membrane, and the membrane was placed in 5\% skim milk diluted with phosphate-buffered saline (PBS) and sealed at room temperature for $2 \mathrm{~h}$. The primary antibody was added to the protein samples and incubated at $4{ }^{\circ} \mathrm{C}$ overnight. $\beta$-actin was taken as the internal reference 
protein. The peroxidase-labeled secondary antibody with 1:2,000 dilution was added and incubated at room temperature for $2 \mathrm{~h}$. After color development, the mixture was placed in a gel imager and photographed. Image-J software was used to quantitatively analyze the gray ratio of protein bands to internal reference.

\section{The detection of chemotherapy sensitivity in vitro by MTT colorimetric assay}

MTT colorimetry is a method used to measure cell survival and growth and reflects the relative number of cells. Cells were collected and seeded in 96-well plates at a density of 4,000 cells $/ 100 \mu \mathrm{L} /$ well. After $12 \mathrm{~h}$ of culture, docetaxel or cisplatin of different concentration gradients were added, and 5 repetitive wells were set for each concentration. After $48 \mathrm{~h}$ of culture with the drugs, $20 \mu \mathrm{L}$ of MTT solution $(5 \mathrm{mg} / \mathrm{mL}$ ) was added to each well. After incubation for $4 \mathrm{~h}$, $100 \mu \mathrm{L}$ of dimethyl sulfoxide (DMSO) was added to each well. The crystallization was fully dissolved by oscillating at low speed for $10 \mathrm{~min}$, and the absorbance value at an optical density (OD) of $490 \mathrm{~nm}$ was detected and recorded. The relative survival rate was calculated as follows: relative survival rate $=(\mathrm{OD}$ value of the experimental group OD value of the blank control group)/(OD value of the negative control group - OD value of the blank control group) $\times 100 \%$. Meanwhile, the resistance index (RI) was calculated as follows: $\mathrm{RI}=50 \%$ inhibition rate (IC50) value of the resistant strain/IC50 value of the parent strain. Subsequently, the cell survival curve was drawn, and the IC50 value was calculated.

\section{The detection of early apoptosis by Annexin V-FITC/PI flow cytometry}

Flow cytometry was used to detect the early apoptosis rate via the Annexin V-FITC/PI double staining method. Adherent cells were digested with trypsin, free of EDTA, and the cells were collected; $10^{6}$ cells were counted and re-suspended with pre-cooled PBS, the supernatant was removed by centrifugation, and the cells were re-suspended with $300 \mu \mathrm{L}$ of binding buffer; $5 \mu \mathrm{L}$ of Annexin V-FITC was added and mixed, and then incubated in the dark for $15 \mathrm{~min}$ at room temperature. For staining before flow cytometry, $5 \mu \mathrm{L}$ of propidium iodide (PI) dye was added under dark conditions. The early apoptosis rate was detected by flow cytometry within $1 \mathrm{~h}$.
The construction of a subcutaneous xenograft tumor model of lung adenocarcinoma in nude mice and the in vivo experiment

Female Balb/c nude mice aged 4 to 6 weeks were purchased from the Department of Comparative Medicine, Jinling Hospital. All experimental nude mice were fed in specificpathogen free (SPF) level environments. The study was performed in a laminar flow tank according to asepsis requirements, which included maintaining purification, constant temperature, and adding food and water at regular times. Animal experiments are conducted in accordance with the norms and guidelines of the Animal Ethics Committee of Jinling Hospital. Four groups of cells (SPC-A1/DTX, SPC-A1/DTX/pGEX6P1/Maspin, SPC-A1, SPC-A1/pGPU6-shMaspin, SPC-A1/DTX, SPC-A1 cells of corresponding empty vectors) were collected at the logarithmic growth stage, washed three times with sterile saline, re-suspended to adjust the cell concentration to $1 \times 10^{6} / \mathrm{mL}$, and inoculated subcutaneously under the right ventral side of the Balb/c nude mice. The tumor growth in the nude mice was closely observed, and the long diameter and short diameter of the tumor were measured and recorded with vernier calipers every other day after tumor formation. When the volume of subcutaneous transplanted tumor reached approximately $100 \mathrm{~mm}^{3}$, docetaxel was given by intraperitoneal injection $(1 \mathrm{mg} / \mathrm{kg})$ every 3 days on three occasions. The tumor growth in the nude mice was monitored and the tumor growth curve was drawn. After 2 weeks of administration, the mice were sacrificed and the tumor was weighed.

\section{The detection of the proliferation ability of cells in vivo by an immunobistochemical method}

All nude mice were sacrificed by cervical dislocation and the tumor tissues of each group were separated. After embedding and fixing, hematoxylin and eosin (HE) staining was performed to confirm the tumor structure, and immunohistochemical staining was used to the detect Ki-67 of maspin.

All animal experiments were performed in accordance with the guidelines for animal care and approved by the Animal Ethics Committee of Jinling Hospital.

\section{The detection of apoptosis by TUNEL staining}

Paraffin sections were made, and then dewaxed, hydrated, 
Table 1 The expression of Maspin in lung adenocarcinoma tissues and normal tissues

\begin{tabular}{cccccccc}
\hline & \multicolumn{2}{c}{ Cancers $(\mathrm{N}=75)$} & & \multicolumn{2}{c}{ Normal $(\mathrm{N}=75)$} & \multirow{2}{*}{ P value } \\
\cline { 2 - 3 } & No. & $\%$ & & No. & $\%$ & \\
\hline Maspin & & & & & & $<0.001^{*}$ \\
High & 23 & 30.67 & & 56 & 74.67 & \\
Low & 52 & 69.33 & & 19 & 25.33 & \\
\hline
\end{tabular}

and soaked in $3 \% \mathrm{H}_{2} \mathrm{O}_{2}$-methanol for $10 \mathrm{~min}$. The working solution of protease $\mathrm{K}$ was added and incubated at room temperature for $15 \mathrm{~min}$, washed twice with PBS, and the excess liquid was sucked up using the filter paper. Next, $50 \mu \mathrm{L}$ of the TUNEL reaction solution was prepared in dark conditions: $5 \mu \mathrm{L}$ of $5 \times$ enzyme concentrated solution was added to $45 \mu \mathrm{L}$ of $5 \times$ labeled solution. The paraffin sections were dripped with the above reaction solution, incubated for $1 \mathrm{~h}$ and washed 3 times. Then, $50 \mu \mathrm{L}$ of the invert agent POD was added, incubated for $20 \mathrm{~min}$, and washed 3 times; $50 \mu \mathrm{L}$ of DAB chromogenic solution was added, incubated for $5 \mathrm{~min}$, and rinsed 3 times. After hematoxylin redyeing, dehydration, and sealing, apoptotic cell morphology was observed under a light microscope.

\section{Statistical methods}

SPSS17.0 statistical software was used for the statistical data analysis. The measurement data are expressed as mean \pm standard deviation, and comparison of mean values between the two groups was performed by $t$ test. A value of $\mathrm{P}<0.05$ was defined as statistically significant.

\section{Results}

\section{The expression of maspin in lung adenocarcinoma and its} clinicopathological correlation analysis

The expression of maspin in tissue chips of 75 patients with lung adenocarcinoma treated with taxane-based chemotherapeutic drugs was investigated to detect the expression of maspin in lung cancer tissues. The results showed that in lung adenocarcinoma tissues, maspin was positively expressed in 23 cases $(30.67 \%$ ), and weakly expressed in 52 cases. However, in paracancerous tissues, maspin was positively expressed in 56 cases $(74.67 \%)$ and weakly expressed in 19 cases (Table 1). The maspin expression and clinicopathological correlation were further analyzed, and results suggested that a low expression of maspin was closely related to lymph node metastasis, pathological grade $(\mathrm{P}=0.008)$, tumor size $(\mathrm{P}<0.001)$, and TNM clinical stage $(\mathrm{P}<0.001)$. However, a low expression of maspin was not significantly correlated with age $(\mathrm{P}=0.572)$ or sex $(\mathrm{P}=0.326)$ (Table 2). The Kaplan-Meier test was conducted to analyze the correlation between maspin expression and overall survival (OS). The results showed that the survival time of patients with high maspin expression was significantly longer than that of patients with low maspin expression (Figure 1), suggesting that maspin could serve as an independent prognostic factor. The above results indicate that maspin plays an important role in the occurrence and development of lung cancer drug resistance.

\section{The expression of maspin in docetaxel-resistant cells}

In order to further study the specific function of maspin in drug-resistant lung squamous cells, we first established the SPC-A1 corresponding multi-drug-resistant cell line, SPC-A1/DTX. The expression of maspin in spC-A1/DTX drug-resistant cells and parent cells, SPC-A1, was detected by fluorescence quantitative PCR (qPCR), and the results showed that the expression of maspin in SPC-A1/DTX was significantly decreased by $0.358 \pm 0.036$, while the expression in SPC-A1 was significantly increased by $0.987 \pm 0.011$ (Figure 2A). The western blot results showed that the expression of maspin in the SPC-A1/DTX drug-resistant cell lines was significantly decreased, while the expression of maspin in SPC-A1 cells was significantly increased (Figure 2B). The lung adenocarcinoma parent cell line, SPC-A1, was treated with docetaxel at different concentrations $(0,3$, and $5 \mu \mathrm{g} / \mathrm{L})$. The expression of maspin was detected by western blot and qPCR assays. The results showed that maspin expression in SPC-A1 cells was $0.722 \pm 0.049$ in response to $3 \mu \mathrm{g} / \mathrm{L}$ docetaxel, and $0.547 \pm 0.042$ in response to $5 \mu \mathrm{g} / \mathrm{L}$ docetaxel, with significant differences compared with the control group (Figure 2C). The lung adenocarcinoma parent cell line, SPC-A1, was treated at different times $(0,3,5$, and 7 days) with $5 \mu \mathrm{g} / \mathrm{L}$ docetaxel. The results showed that maspin expression in SPC-A1 cells was $0.653 \pm 0.039,0.322 \pm 0.028$, and $0.284 \pm 0.020$, respectively on day 3,5 , and 7 , which was significantly different compared with the control group $(\mathrm{P}<0.01)$ (Figure $2 D)$. The above results suggest that the expression of maspin in the parent cell line decreases gradually with the increase of docetaxel concentration and the extension of drug action time, indicating that the downregulated expression of 
Table 2 The correlation between Maspin expression and clinical characteristics of patients with lung adenocarcinoma

\begin{tabular}{|c|c|c|c|c|c|c|c|}
\hline & \multicolumn{2}{|c|}{ Cases $(\mathrm{N}=75)$} & \multicolumn{2}{|c|}{ Maspin high expression $(\mathrm{N}=23)$} & \multicolumn{2}{|c|}{ Maspin low expression $(\mathrm{N}=52)$} & $P$ value \\
\hline Age & & & & & & & 0.572 \\
\hline$\geq 59$ years & 40 & 53.33 & 13 & 56.52 & 27 & 51.92 & \\
\hline$<59$ years & 34 & 45.33 & 9 & 39.13 & 25 & 48.08 & \\
\hline Gender & & & & & & & 0.326 \\
\hline Male & 39 & 52 & 10 & 43.48 & 29 & 55.77 & \\
\hline Female & 36 & 48 & 13 & 56.52 & 23 & 44.23 & \\
\hline Pathological staging & & & & & & & $0.008^{*}$ \\
\hline Deletion* & 4 & 5.33 & 2 & 8.7 & 2 & 3.85 & \\
\hline Tumor size & & & & & & & $<0.001^{*}$ \\
\hline $\mathrm{T} 1$ & 21 & 28 & 15 & 65.22 & 6 & 11.54 & \\
\hline $\mathrm{T} 2$ & 42 & 56 & 8 & 34.78 & 34 & 65.38 & \\
\hline T3 & 8 & 10.67 & 0 & 0 & 8 & 15.38 & \\
\hline $\mathrm{T} 4$ & 4 & 5.33 & 0 & 0 & 4 & 7.69 & \\
\hline TNM classification & & & & & & & $<0.001^{\star}$ \\
\hline I & 34 & 45.33 & 19 & 82.61 & 15 & 28.85 & \\
\hline
\end{tabular}

*, $\mathrm{P}<0.05$.

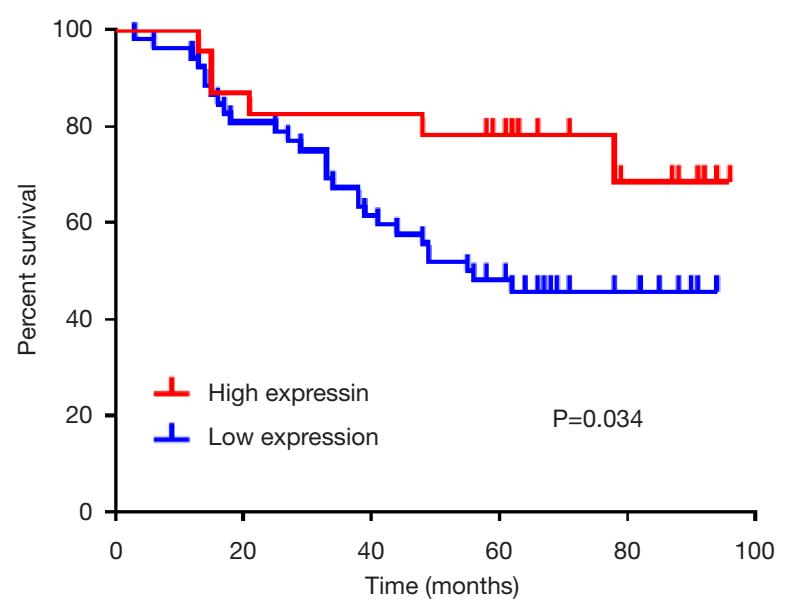

Figure 1 The Kaplan-Meier test was conducted to analyze and count the correlation between maspin expression and overall survival (OS). maspin may be related to the decreased sensitivity of lung adenocarcinoma to chemotherapy drugs.

\section{The effect of docetaxel on maspin distribution in lung cancer cells}

To further investigate the effect of docetaxel on the distribution of maspin in lung cancer cells, the distribution of maspin in the cytoplasm and nucleus was measured by a nucleo-cytoplasmic separation assay. The results showed that in the chemotherapy-sensitive cell line, SPC-A1, maspin was mainly distributed in the nucleus: $66.2 \%$ (nucleus) and $33.8 \%$ (cytoplasm). Meanwhile, in the chemotherapy-resistant cell line, SPC-A1/DTX, maspin was mainly expressed in the cytoplasm: $21.3 \%$ (nucleus) and $78.7 \%$ (cytoplasm) (Figure 3A). Fluorescence in 
A

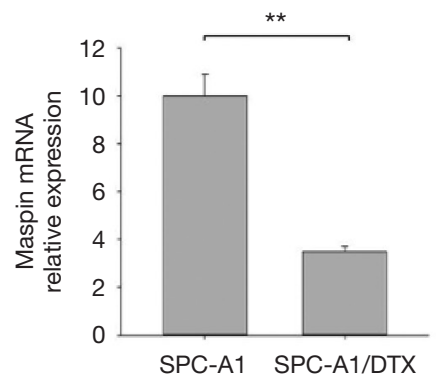

C

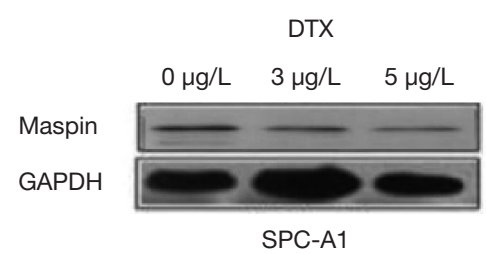

- SPC-A1

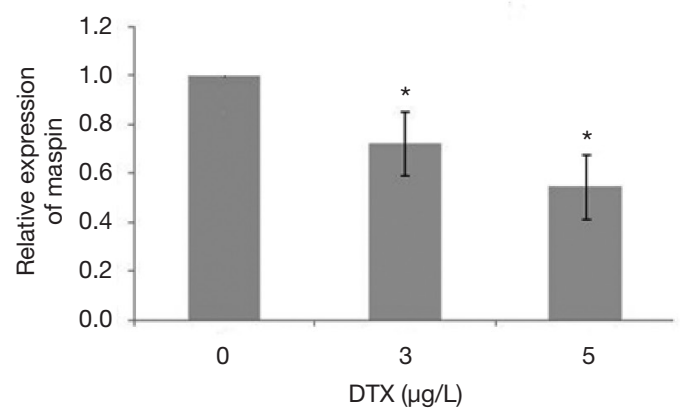

B

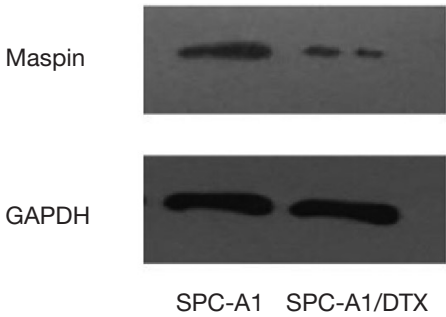

D

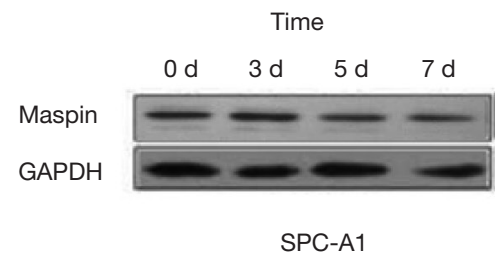

- SPC-A1

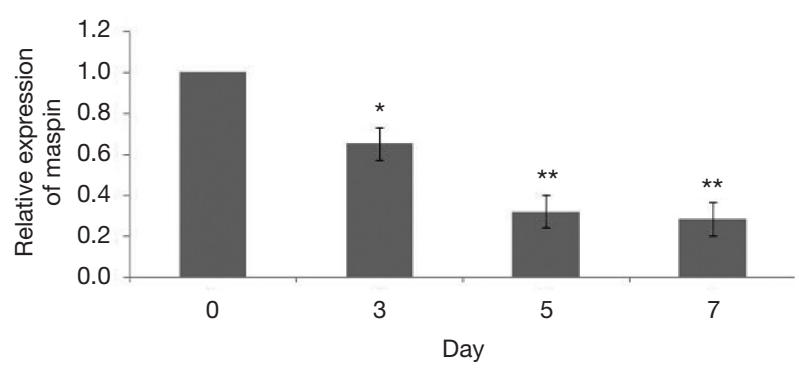

Figure 2 Effect of docetaxel on maspin expression in lung adenocarcinoma cells. (A) Detection of the expression of maspin in lung adenocarcinoma SPC-A1/docetaxel (DTX)-resistant cells and parent cells, SPC-A1, by fluorescence qPCR. (B) Detection of the expression of maspin in lung adenocarcinoma SPC-A1/DTX-resistant cells and the parent cell line, SPC-A1, by western blot assay. (C) Lung adenocarcinoma parent cell lines were treated with different concentrations of DTX $(0,3$, and $5 \mu \mathrm{g} / \mathrm{L})$. Western blot (figure above) and qPCR (figure below) showed that the expression of maspin decreased with the increase of DTX concentration, with the protein expression level of GAPDH being used as an internal reference. (D) Lung adenocarcinoma parent cell lines were treated with $5 \mu \mathrm{g} / \mathrm{L}$ DTX. Western blot (above figure) and qPCR (figure below) showed that the expression of maspin decreased with the extension of drug action time, with the protein expression level of GAPDH being used as an internal reference. * $\mathrm{P}<0.05$; ${ }^{* *}, \mathrm{P}<0.01$.

situ hybridization (FISH) was used to further detect the subcellular distribution and localization of maspin. The RNA-FISH results showed that maspin expression was distributed in the nucleus and cytoplasm. In sensitive cell lines, maspin was mainly located in the nucleus, while in drug-resistant cell lines, maspin was mainly distributed in the cytoplasm (Figure 3B). The above experimental results suggest that docetaxel could affect maspin's intracellular localization, leading to the emergence of drug resistance in lung cancer cells.

\section{The overexpression or knockdown of maspin affected the sensitivity of lung cancer cells to docetaxel}

In order to further investigate the role of maspin in the formation of a drug-resistant phenotype in lung adenocarcinoma cells, the maspin overexpression vector pGEX6P1/Maspin was transfected in the lung adenocarcinoma drug-resistant cell line, SPC-A1/DTX, and a SPC-A1/DTX cell line that could stably express maspin was constructed in addition to the control SPC-A1/DTX 

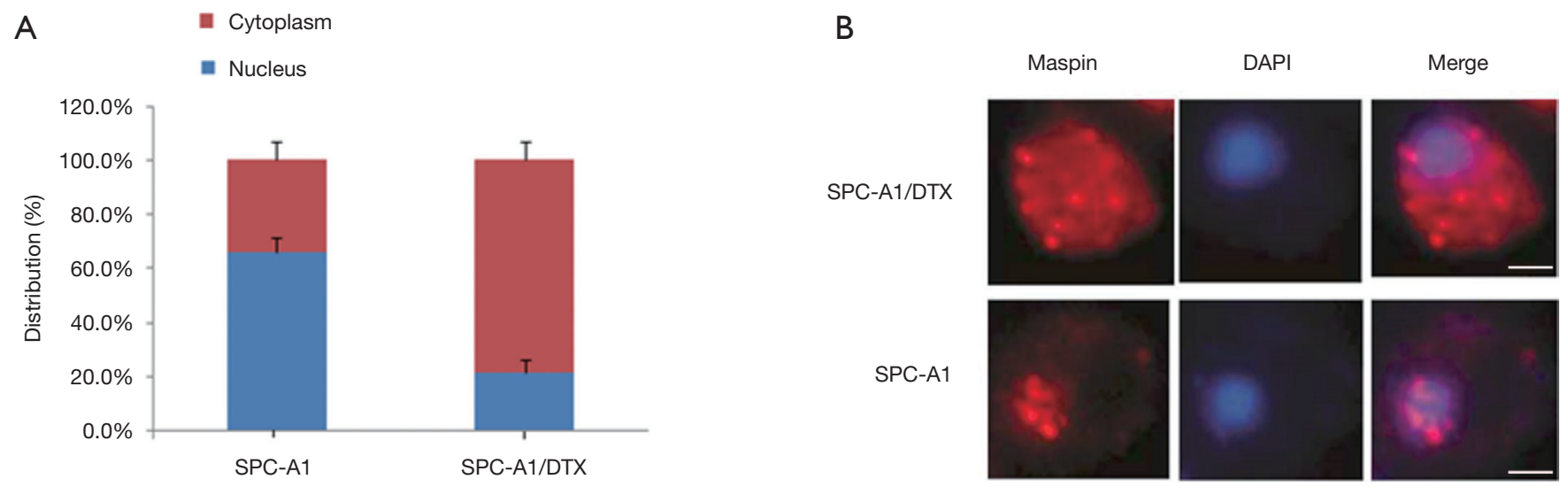

Figure 3 The effect of docetaxel on maspin distribution in lung cancer cells. (A) After the total mRNA in the nucleus and cytoplasm was isolated respectively, the expression levels of maspin in the nucleus and cytoplasm were detected by qRT-PCR assay. (B) RNA in situ hybridization assay: small RNA fragment probes that were complementary with maspin and labeled with specific fluorescence were synthesized, and the localization of maspin in subcells was detected by fluorescence in situ hybridization.

cell line. Real-time fluorescence qRT-PCR was used to detect the overexpression efficiency of maspin in these two cells, and maspin was overexpressed in drug-resistant lung adenocarcinoma cells (Figure 4A,B). In addition, Maspininterfering vector pGPU6-shMaspin was transfected into the lung adenocarcinoma sensitive cell line, SPC-A1, and the expression of maspin was artificially interfered to observe its effect on the formation of a chemotherapyresistance phenotype in lung adenocarcinoma sensitive cells. Real-time fluorescent qRT-PCR was used to detect the interference efficiency, and the results showed that the interference plasmid transfection effect was verified as ideal (Figure 4C,D).

Fistly, the MTT assay was used to detect the growth inhibition effect of three chemotherapy drugs (docetaxel, cisplatin, and gemcitabine) on lung adenocarcinoma cells, and the results were expressed as the IC50 value. The results showed that after maspin was overexpressed, the IC50 values of SPC-A1/DTX/pGEX6P1/Maspin for DTX, DDP, and Gem were $312.46 \pm 20.70 \mu \mathrm{g} / \mathrm{L}, 9.81 \pm 1.01 \mathrm{mg} / \mathrm{L}$, and $2.75 \pm 1.01 \mathrm{mg} / \mathrm{L}$, respectively, which were significantly lower than the IC50 values of SPC-A1 cells in the control group $(575.23 \pm 54.3 \mu \mathrm{g} / \mathrm{L}, 15.3 \pm 1.72 \mathrm{mg} / \mathrm{L}$, and $5.31 \pm 0.79 \mathrm{mg} / \mathrm{L})$ $(\mathrm{P}<0.01)$ (Figure $4 E)$. These results suggest that transfection of the maspin overexpression vector could upregulate the expression of maspin in drug-resistant lung adenocarcinoma cell lines and increase the sensitivity of chemotherapy.

Secondly, The MTT assay was used to detect the growth inhibition effect of three chemotherapy drugs (docetaxel, cisplatin, and gemcitabine) on lung adenocarcinoma cells, and the results were expressed as IC50 values. The results showed that, after interference of maspin, the IC50 values of SPC-A1/pGPU6-shMaspin cells for DTX, DDP, and Gem were $303.23 \pm 28.15 \mu \mathrm{g} / \mathrm{L}, 9.56 \pm 0.89 \mathrm{mg} / \mathrm{L}$, and $3.42 \pm 0.54 \mathrm{mg} / \mathrm{L}$, respectively, which were significantly higher than the IC50 values of SPC-A1 cells in the control group $(109.46 \mu \mathrm{g} / \mathrm{L}, 5.79 \pm 0.64 \mathrm{mg} / \mathrm{L}$, and $1.18 \pm 0.73 \mathrm{mg} / \mathrm{L})$ $(\mathrm{P}<0.01)$. These results suggest that transfection of the maspin-interfering vector could downregulate the expression of maspin in lung adenocarcinoma sensitive cell lines and increase drug resistance (Figure 4E).

\section{The overexpression or knockdown of maspin affected cell apoptosis of lung cancer cells induced by chemotherapy drugs (docetaxel, cisplatin, and gemcitabine)}

Flow cytometry detection results showed that the apoptosis rate of SPC-A1/DTX cells with maspin overexpression was markedly higher than that of the control group $(19.62 \% \pm 1.29 \%$ vs. $5.12 \% \pm 0.80 \%)$ after $50 \mu \mathrm{g} / \mathrm{L}$ of docetaxel treatment. After $3 \mu \mathrm{g} / \mathrm{L}$ of docetaxel treatment, the apoptosis rate of SPC-A1 cells with maspin knockdown was significantly lower than that of the control group (3.36\% $\pm 0.30 \%$ vs. $9.59 \% \pm 0.85 \%$ ) (Figure 5). After $25 \mu \mathrm{g} / \mathrm{L}$ of cisplatin treatment, the apoptosis rate of SPC-A1/ DTX cells with maspin overexpression was significantly higher than that of the control group $(15.32 \% \pm 1.89 \%$ vs. $3.86 \% \pm 0.20 \%$ ), while the apoptosis rate of SPC-A1 cells 
A

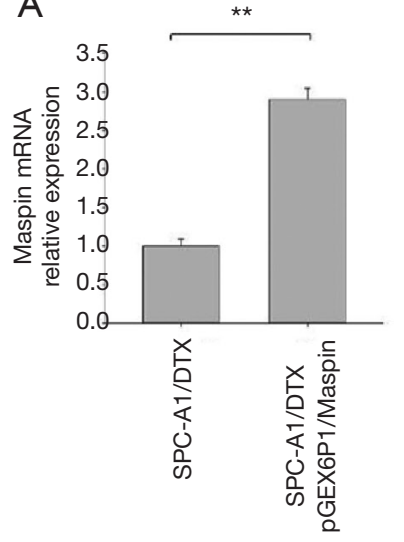

$\mathrm{E}$

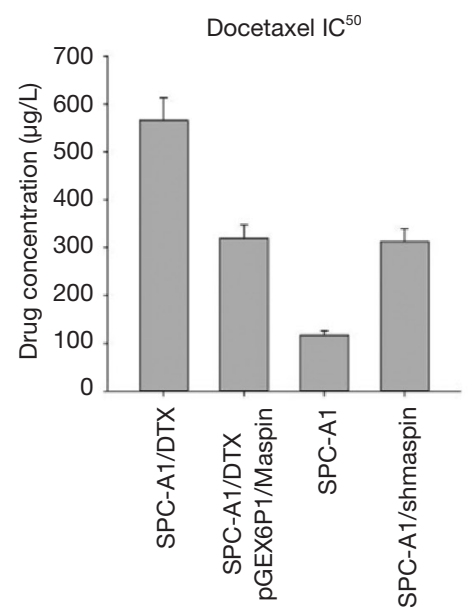

B
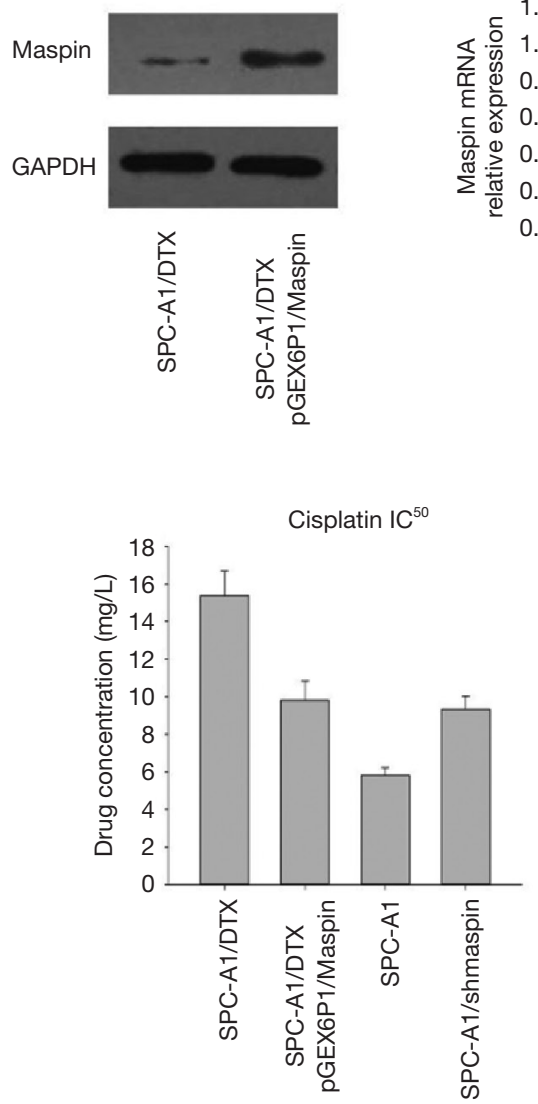

C

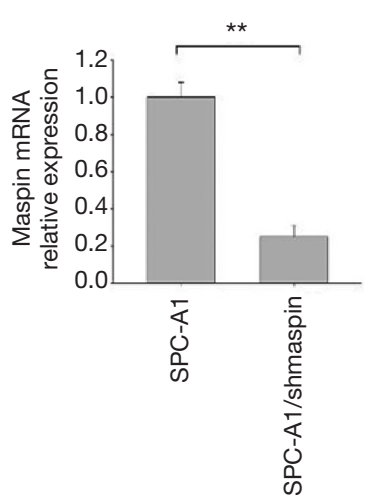

D

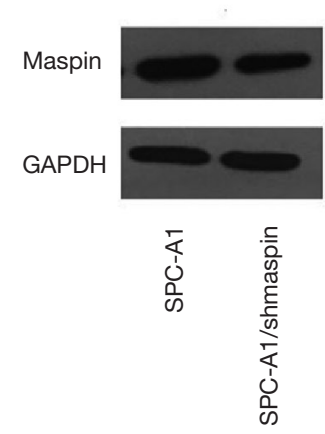

Figure 4 The overexpression or knockdown of maspin can affect the sensitivity of lung cancer cells to docetaxel. Fluorescence qPCR (A) and western blot (B) were used to detect the overexpression of maspin in the lung adenocarcinoma-resistant cell line, SPC-A1/docetaxel (DTX). Fluorescence qPCR (C) and western blot (D) were used to detect the interference efficiency of the lung adenocarcinoma sensitive cell line, SPC-A1, after maspin interference. (E) The MTT assay was used to detect the influence of lung adenocarcinoma drug-resistant cell lines and parent cell lines with maspin overexpression or knockdown on IC50 values of DTX, DDP, and Gem. **, P<0.01.

with maspin knockdown was significantly lower than that of the control group $(2.45 \% \pm 0.50 \%$ vs. $8.19 \% \pm 0.72 \%)$ after $1.5 \mu \mathrm{g} / \mathrm{L}$ of cisplatin treatment (Figure 6). After $250 \mu \mathrm{g} / \mathrm{L}$ of gemcitabine treatment, the apoptosis rate of SPC-A1/ DTX cells with maspin overexpression was significantly higher than that of the control group $(17.32 \% \pm 1.46 \%$ vs. $2.59 \% \pm 0.30 \%$ ), while the apoptosis rate of SPC-A1 cells with maspin knockdown after $15 \mu \mathrm{g} / \mathrm{L}$ gemcitabine treatment was significantly lower than that of the control group $(1.95 \% \pm 0.09 \%$ vs. $5.69 \% \pm 0.60 \%$ ) (Figure 7 ). All of the above results indicate that upregulation of maspin could promote early apoptosis induced by chemotherapy, while downregulation of maspin could inhibit early apoptosis induced by chemotherapy.

\section{Verification of the sensitivity of maspin expression to chemotherapy in lung adenocarcinoma cells by nude mouse experiments in vivo}

The above results confirm that maspin can reverse chemotherapy-resistant phenotype formations in lung adenocarcinoma in vitro. In order to confirm changes in maspin's sensitivity to chemotherapy in human lung adenocarcinoma in vivo, we screened the cell group that was stably transfected with maspin overexpression, interference, and the corresponding control, and constructed a nude 


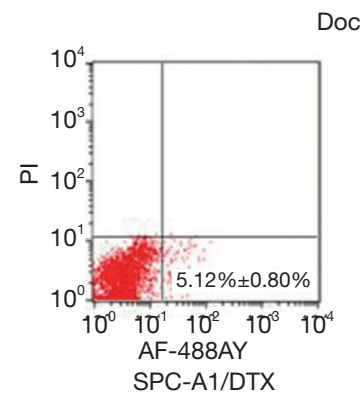

Docetaxel
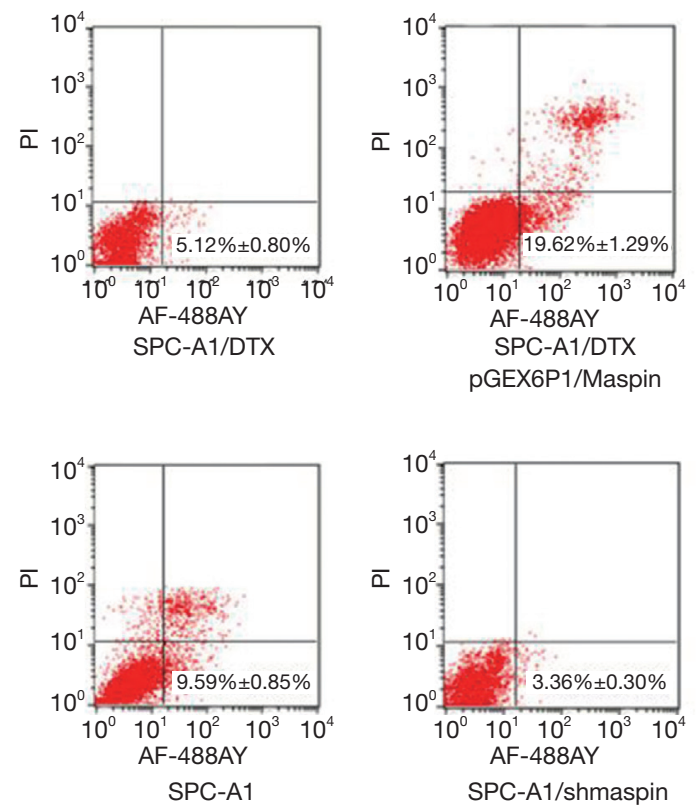

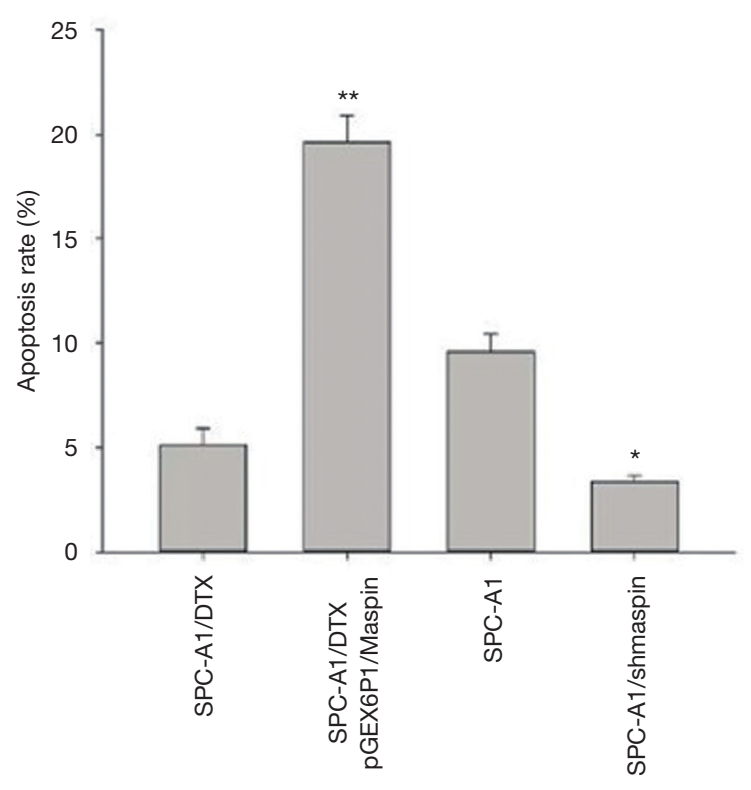

Figure 5 The detection of the apoptosis rate in human lung adenocarcinoma-transfected cell lines with docetaxel by flow cytometry and the statistical analysis. *, $\mathrm{P}<0.05 ;{ }^{* *}, \mathrm{P}<0.01$.

mouse subcutaneous xenograft tumor model. After DTX treatment, the tumor volume of the overexpressed maspin group was significantly smaller than that of the control group, and the tumor volume of the interfered maspin group was significantly larger than that of the control group $(\mathrm{P}<0.05)$ (Figure 8A,B). After the nude mice were sacrificed, the tumor-bearing tissues were stripped and weighed. The results showed that, compared with the control group, the subcutaneous transplantation tumor of drug-resistant cells with a high expression of maspin increased their sensitivity to docetaxel, while the tumor weight was significantly reduced and was similar to the transplantation tumor of the sensitive cell group (Figure 8C).

Further immunohistochemical assay showed that in the four groups treated with DTX, the proliferation ability of cells treated with DTX was decreased compared with drugresistant cell lines when maspin was upregulated, while the proliferation ability of cells treated with DTX was increased compared with the sensitive cell lines. This suggests that the upregulation of maspin could reduce the proliferation capacity of lung adenocarcinoma cells in vivo, and this effect is more obvious after DTX chemotherapy (Figure 9A). TUNEL staining results showed that after DTX treatment, the apoptosis rate of the overexpression group was $45.17 \%$, which was significantly higher than that of the control group $(20.25 \%)$. Conversely, after DTX treatment, the apoptosis rate of the interference group was $40.03 \%$, which was significantly lower than that of the control group $(69.98 \%)$. These results indicate that upregulation of maspin expression could significantly increase the proapoptotic effect of DTX (Figure 9B).

\section{Discussion}

Lung cancer is a condition characterized by malignant tumor growth and is the leading cause of morbidity and mortality in the world (1). However, the multidrug resistance of malignant tumors directly reduces the sensitivity of tumor cells to multiple chemotherapy drugs, which is a major cause of ineffective chemotherapy (4). This study demonstrated the correlation between maspin and the clinical prognosis of lung adenocarcinoma patients. Our functional experiments showed that interference or overexpression of maspin could significantly affect the sensitivity of lung adenocarcinoma cells to different chemotherapy drugs. In vivo nude mouse experiments also showed increased sensitivity to docetaxel after subcutaneous transplantation of drug-resistant tumor cells showed an 


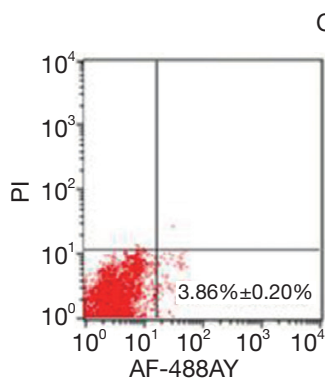

Cisplatin

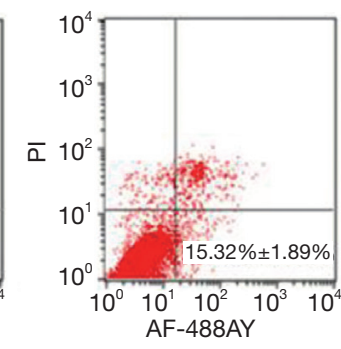

SPC-A1/DTX

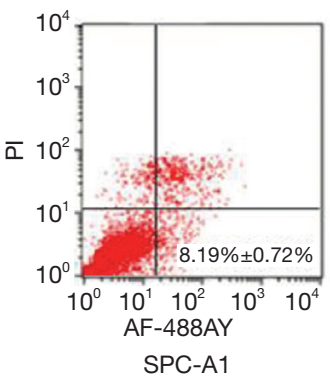

SPC-A1/DTX PGEX6P1/Maspin

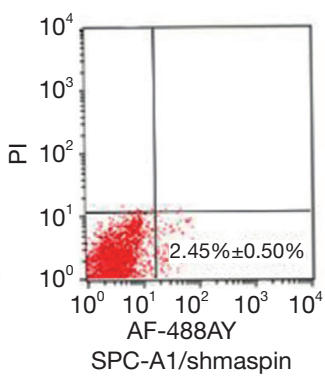

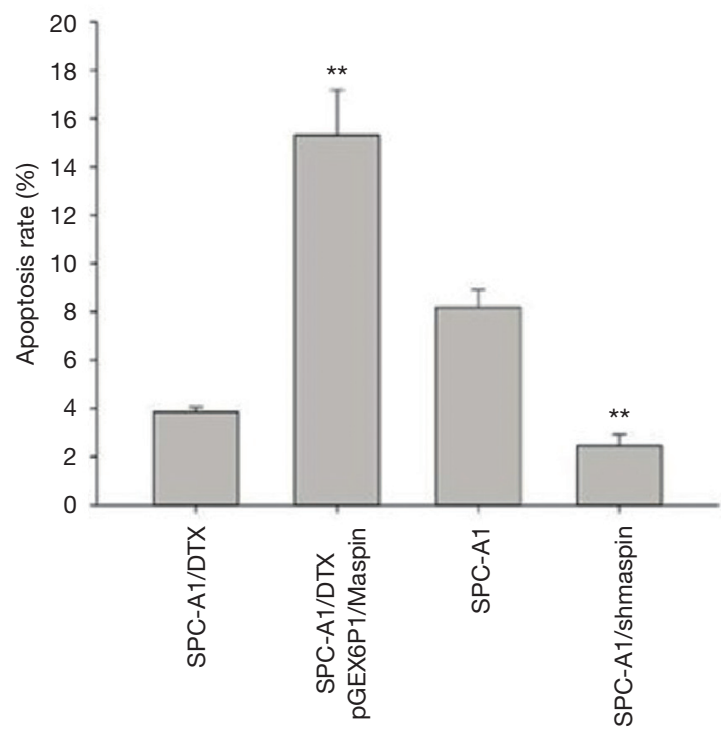

Figure 6 The detection of the apoptosis rate in human lung adenocarcinoma-transfected cell lines with cisplatin by flow cytometry and the statistical analysis. ${ }^{* *}, \mathrm{P}<0.01$.

overexpression of maspin, and a significant reduction in tumor volume and weight.

In recent years, a large number of studies have found that the formation of drug resistance in tumor cells is a multi-factor, multi-stage, and long-term process of accumulation and change. This includes the regulation of genetics and epigenetics, which involves the whole process of gene expression and regulation on a transcriptional, post-transcriptional, and protein translation level (16-19). The preliminary experimental results in our laboratory demonstrated that the increased expression of miR-200b can significantly reverse the chemotherapy-resistance characteristics of lung adenocarcinoma cells in vivo and in vitro by inducing the downregulation of E2F3 gene expression (20). In addition, the docetaxel-resistant cell line of human lung cancer SPC-A1 cells, named SPC-A1/DTX, was successfully established in our laboratory by gradually increasing the concentration of docetaxel in vitro. Moreover, multi-drug resistance was identified by several methods including MTT, flow cytometry, growth curve mapping, and chromosome karyotype analysis (17). Genome-wide cDNA chip analysis was performed on parent SPC-A1 cells and drug-resistant SPC-A1/DTX cells, and data mining revealed that maspin was significantly differentially expressed between parent SPC-A1 cells and drug-resistant
SPC-A1/DTX cells, with a downregulated multiple of up to 60.9 , ranking first among 506 genes with downregulated expression (21).

The maspin gene is located in $18 \mathrm{q} 21.3-\mathrm{q} 23$, and the expression product has 375 amino acids (22). A large number of recent studies have shown that a reduced maspin level in prostate cancer is associated with higher recurrence, lower survival rate, lower tumor differentiation, and advancement of metastasis (23). In this study, maspin was found to have low expression in tissue chip samples of 75 patients diagnosed with lung adenocarcinoma and treated with a taxus chemotherapy regimen. Further analysis showed that maspin was weakly expressed in chemotherapy-resistant type cells, which in turn are associated with lymph node metastasis, recurrence, and poor prognosis. Survival analysis confirmed that a low expression of maspin was closely related to late TNM staging, mass size, and lymph node metastasis, suggesting that maspin could be an independent prognostic factor in lung adenocarcinoma. In addition, maspin is involved in regulating the tumor-killing effect of chemotherapy drugs. Jiang et al. found that the sensitivity of breast cancer cells to astrocyclosporin-induced apoptosis increased after the introduction of maspin (24). Ben Shachar et al. found that maspin could enhance the sensitivity of osteosarcoma cells to docetaxel and cisplatin by enhancing 

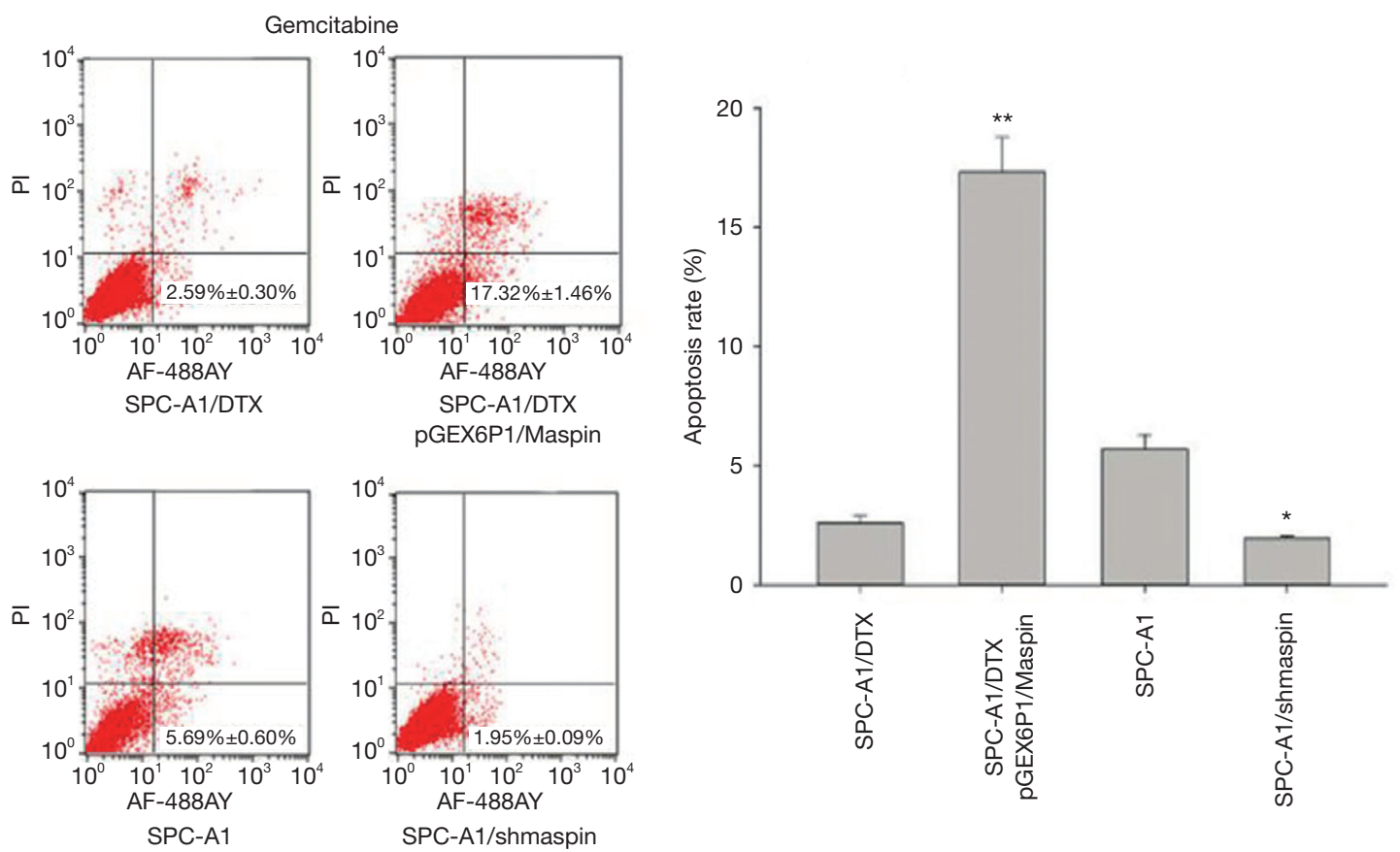

Figure 7 Detection of the apoptosis rate in human lung adenocarcinoma-transfected cell lines with gemcitabine by flow cytometry and the statistical analysis. *, $\mathrm{P}<0.05 ;{ }^{* *}, \mathrm{P}<0.01$.

E2F1-induced apoptosis (25). Chen et al. found that maspin could increase the sensitivity of bladder cancer cells to cisplatin, and that the apoptosis of cancer cells increased after transfection with maspin (26). In this study, it was found that the expression of maspin was significantly low in drug-resistant cells, and the expression of maspin decreased progressively with the increase in docetaxel concentration and the extension of time. Overexpression of maspin in drug-resistant lung adenocarcinoma cells can reduce the $50 \%$ inhibition rate (IC50) of docetaxel to drug-resistant cells, increase the sensitivity to docetaxel, and can lead to an increased rate of apoptosis. Conversely, knockdown of maspin expression in parent cells can reduce the drug sensitivity of parent cells to docetaxel, increase the IC50 of docetaxel against drug-resistant cells, enhance the proliferation ability of parent cells in vitro, and reduce apoptosis. This was further verified in the xenograft model of nude mice. The mice that received chemotherapy in the tumor-bearing group with maspin overexpression demonstrated significant reductions in tumor weight, the growth curve of the xenograft tumor, and in the positive rate of the proliferation index of $\mathrm{Ki}-67$, whereas the significant nuclear fragment presentation indicated an apoptosis increase. However, after the mice in the maspin knockdown group received chemotherapy, the growth curve and tumor weight of the transplanted tumor increased, as did the positive rate of the proliferation index of Ki-67, whereas the apoptosis rate was decreased. This suggests that the increased expression of maspin could have a synergistic effect with docetaxel by inhibiting the tumor-generating capacity of SPC-A1/DTX cells, and significantly improving the chemotherapy sensitivity of docetaxel, thus reducing the Ki-67 positive rate in vivo, and promoting nuclear division.

In conclusion, this study is the first to demonstrate that maspin is poorly expressed in tissue chip specimens of patients with lung adenocarcinoma who have received taxus chemotherapy, and hence is involved in the creation of drug resistance in lung adenocarcinoma. Maspin is weakly expressed in chemotherapy-resistant drugs, and is associated with lymph node metastasis, recurrence, and poor prognosis. Survival analysis confirmed that a low expression of maspin is closely related to late TNM staging, mass size, and lymph node metastasis, and that maspin could be an independent prognostic factor in lung adenocarcinoma. The current study further demonstrated that knockdown or overexpression of maspin significantly affects the 

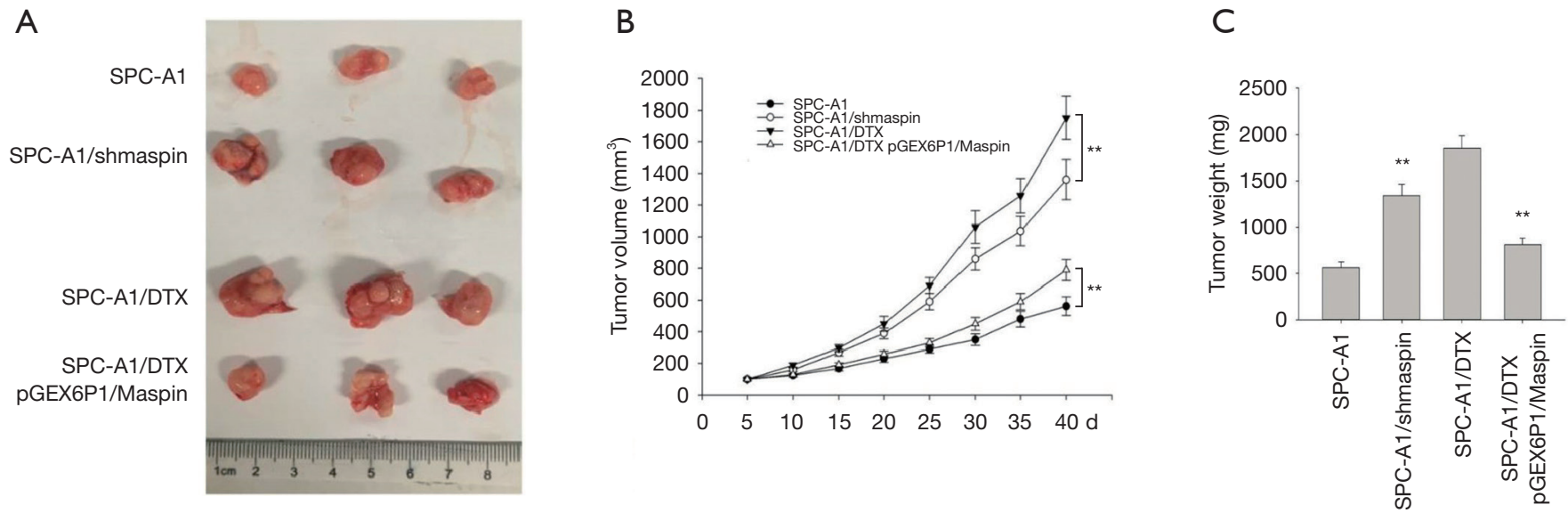

Figure 8 In vivo nude mouse experiments were performed to screen cells with stable transfection of overexpression, interference, and corresponding control, and to construct a model of a subcutaneous xenograft tumor in nude mice. (A) After docetaxel (DTX) treatment, nude mice were sacrificed to strip the tumor-bearing tissues of each group. (B) The tumor bearing growth curves of each group after DTX treatment. (C) The effect of DTX treatment on tumor-bearing weight in each group. ${ }^{* *}, \mathrm{P}<0.01$.

A

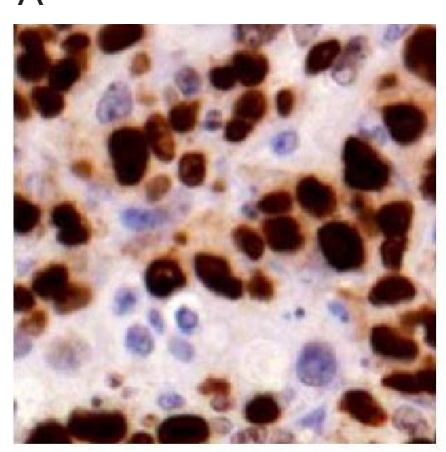

SPC-A1/DTX

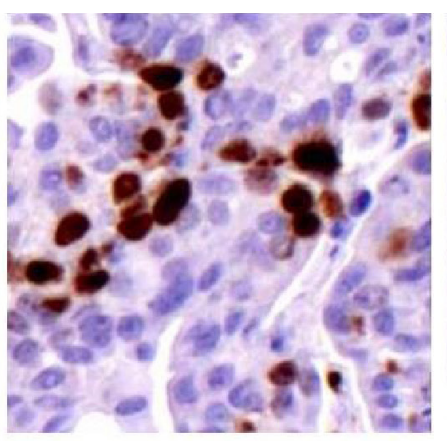

SPC-A1/DTX pGEX6P1/Maspin

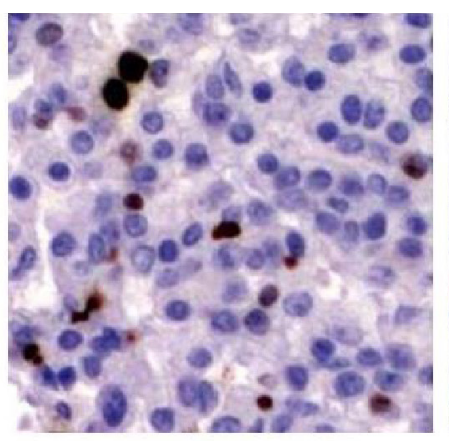

SPC-A1

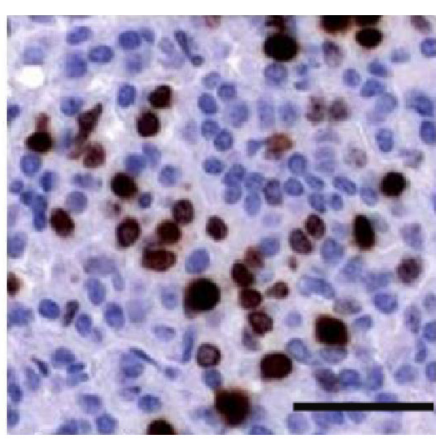

SPC-A1/shmaspin

\section{B}

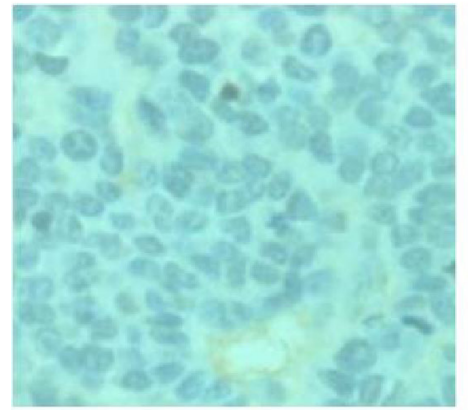

SPC-A1/DTX

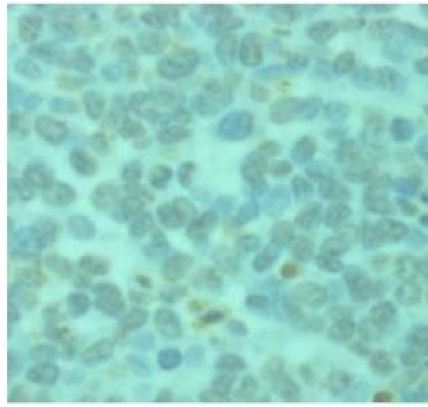

SPC-A1/DTX pGEX6P1/Maspin

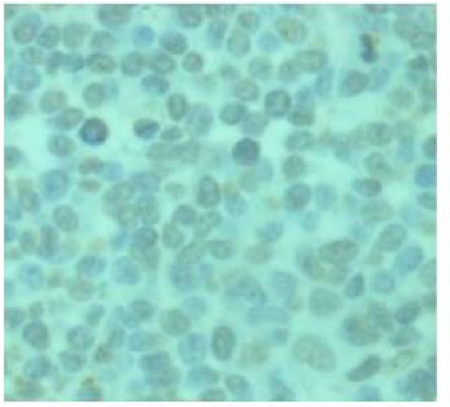

SPC-A1

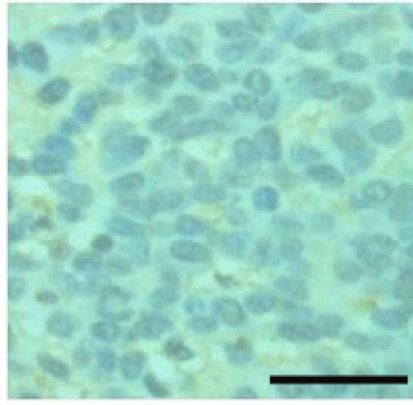

SPC-A1/shmaspin

Figure 9 Upregulation of maspin expression significantly reduced the proliferation of SPC-A1/DTX cells. (A) Immunohistochemical were used to detect the expression of Ki-67 in paraffin sections of transplanted tumor tissues (200× magnification). (B) TUNEL was used to detect apoptotic cells in paraffin sections of transplanted tumor tissues (200× magnification). 
chemotherapeutic sensitivity of lung adenocarcinoma cells. The results of this study indicate that maspin may have a role as a molecular marker or target that can be used for early diagnosis or targeted therapy of lung adenocarcinoma resistance.

\section{Acknowledgments}

Funding: None.

\section{Footnote}

Reporting Checklist: The authors have completed the ARRIVE reporting checklist. Available at http://dx.doi. org/10.21037/atm-20-7053

Data Sharing Statement: Available at http://dx.doi. org/10.21037/atm-20-7053

Conflicts of Interest: All authors have completed the ICMJE uniform disclosure form (available at http://dx.doi. org/10.21037/atm-20-7053). The authors have no conflicts of interest to declare.

Ethical Statement: The authors are accountable for all aspects of the work in ensuring that questions related to the accuracy or integrity of any part of the work are appropriately investigated and resolved. The study was conducted in accordance with the Declaration of Helsinki (as revised in 2013). All animal experiments were performed in accordance with the guidelines for animal care and approved by the Animal Ethics Committee of Jinling Hospital.

Open Access Statement: This is an Open Access article distributed in accordance with the Creative Commons Attribution-NonCommercial-NoDerivs 4.0 International License (CC BY-NC-ND 4.0), which permits the noncommercial replication and distribution of the article with the strict proviso that no changes or edits are made and the original work is properly cited (including links to both the formal publication through the relevant DOI and the license). See: https://creativecommons.org/licenses/by-nc-nd/4.0/.

\section{References}

1. Rodriguez-Canales J, Parra-Cuentas E, Wistuba II. Diagnosis and Molecular Classification of Lung Cancer. Cancer Treat Res 2016;170:25-46.
2. Naylor EC, Desani JK, Chung PK. Targeted Therapy and Immunotherapy for Lung Cancer. Surg Oncol Clin N Am 2016;25:601-9.

3. Hirsch FR, Scagliotti GV, Mulshine JL, et al. Lung cancer: current therapies and new targeted treatments. Lancet 2017;389:299-311.

4. Chau B, Shinde A, Amini A. Neoadjuvant therapy in localized non-small cell lung cancer: can we do better than chemotherapy? Transl Cancer Res 2019;8:S633-5.

5. Giroux-Leprieur E, Costantini A, Ding VW, et al. Hedgehog Signaling in Lung Cancer: From Oncogenesis to Cancer Treatment Resistance. Int J Mol Sci 2018;19:2835.

6. Liang J, Lu T, Chen Z, et al. Mechanisms of resistance to pemetrexed in non-small cell lung cancer. Transl Lung Cancer Res 2019;8:1107-18.

7. Qin X, Yu S, Zhou L, et al. Cisplatin-resistant lung cancer cell-derived exosomes increase cisplatin resistance of recipient cells in exosomal miR-100-5p-dependent manner. Int J Nanomedicine 2017;12:3721-33.

8. Liang SQ, Bührer ED, Berezowska S, et al. mTOR mediates a mechanism of resistance to chemotherapy and defines a rational combination strategy to treat KRASmutant lung cancer. Oncogene 2019;38:622-36.

9. Zou Z, Anisowicz A, Hendrix MJ, et al. Maspin, a serpin with tumor-suppressing activity in human mammary epithelial cells. Science 1994;263:526-9.

10. Liu J, Yin S, Reddy N, et al. Bax mediates the apoptosissensitizing effect of maspin. Cancer Res 2004;64:1703-11.

11. Cella N, Contreras A, Latha $\mathrm{K}$, et al. Maspin is physically associated with (beta) 1 integrin regulating cell adhesion in mammary epithelial cells. FASEB J 2006;20:1510-2.

12. Yin S, Lockett J, Meng Y, et al. Maspin retards cell detachment via a novel interaction with the urokinasetype plasminogen activator/urokinase-type plasminogen activator receptor system. Cancer Res 2006;66:4173-81.

13. Maekawa T, Shinagawa T, Sano Y, et al. Reduced levels of ATF-2 predispose mice to mammary tumors. Mol Cell Biol 2007;27:1730-44.

14. Liu D, Li W, Zhong F, et al. METTL7B Is Required for Cancer Cell Proliferation and Tumorigenesis in NonSmall Cell Lung Cancer. Front Pharmacol 2020;11:178.

15. Gatenby R, Brown J. The Evolution and Ecology of Resistance in Cancer Therapy. Cold Spring Harb Perspect Med 2018;8:a033415.

16. Siegfried Z, Karni R. The role of alternative splicing in cancer drug resistance. Curr Opin Genet Dev 2018;48:16-21. 
17. Sun H, Chen LB. Mechanism of drug resistance identified in human lung adenocarcinoma cell line SPC-A1 selected for resistance to docetaxel. Chinese Journal of Cancer Research 2009;21:207-16.

18. Li W, Yu KN, Bao L, et al. Non-thermal plasma inhibits human cervical cancer HeLa cells invasiveness by suppressing the MAPK pathway and decreasing matrix metalloproteinase-9 expression. Sci Rep 2016;6:19720.

19. Feng B, Wang R, Song HZ, et al. MicroRNA-200b reverses chemoresistance of docetaxel-resistant human lung adenocarcinoma cells by targeting E2F3. Cancer 2012;118:3365-76.

20. Wang R, Huang J, Feng B, et al. Identification of ING4 (inhibitor of growth 4) as a modulator of docetaxel sensitivity in human lung adenocarcinoma. Mol Med 2012;18:874-86.

21. Dzinic SH, Bernardo MM, Oliveira DS, et al. Tumor suppressor maspin as a modulator of host immune response to cancer. Bosn J Basic Med Sci 2015;15:1-6.

Cite this article as: Sun Q, Zhang K, Li H, Chen W, Liu L, Huang G, Zhang Q, Wang J, Lu L, Chen L, Wang R. The overexpression of maspin increases the sensitivity of lung adenocarcinoma drug-resistant cells to docetaxel in vitro and in vivo. Ann Transl Med 2020;8(22):1522. doi: 10.21037/atm-207053
22. Machtens S, Serth J, Bokemeyer C, et al. Expression of the p53 and Maspin protein in primary prostate cancer: correlation with clinical features. Int J Cancer 2001;95:337-42.

23. Jiang N, Meng Y, Zhang S, et al. Maspin sensitizes breast carcinoma cells to induced apoptosis. Oncogene 2002;21:4089-98.

24. Ben Shachar B, Feldstein O, Hacohen D, et al. The tumor suppressor maspin mediates E2F1-induced sensitivity of cancer cells to chemotherapy. Mol Cancer Res 2010;8:363-72.

25. Chen J, Wang L, Tang Y, et al. Maspin enhances cisplatin chemosensitivity in bladder cancer T24 and 5637 cells and correlates with prognosis of muscle-invasive bladder cancer patients receiving cisplatin based neoadjuvant chemotherapy. J Exp Clin Cancer Res 2016;35:2 .

(English Language Editor: D. Fitzgerald; Quality Control Editor: J. Gray) 